\title{
Portuguese category norms for children
}

\author{
Paula Carneiro \\ Universidade Lusófona de Humanidades e Tecnologias, Lisbon, Portugal \\ Pedro Albuquerque \\ Universidade do Minho, Braga, Portugal \\ AND \\ ANGel FerNaNDEZ \\ Universidad de Salamanca, Salamanca, Spain
}

\begin{abstract}
This study presents Portuguese category norms for children of three different age groups: preschoolers (3- to 4-year-olds), second graders (7- to 8-year-olds), and preadolescents (11- to 12-year-olds). Three hundred Portuguese children (100 in each group) completed an exemplar-generation task. Preschoolers generated exemplars for 13 categories, second graders generated exemplars for 17 categories, and preadolescents generated exemplars for 21 categories. For each group, responses within each category were organized according to frequency of production in order to derive exemplar-production norms for sets of tested categories. The results also included information about the number of responses and exemplars, idiosyncratic and inappropriate responses, and commonality and diversity indexes for all the categories. A comparison of these children's norms with the Portuguese adult norms was also presented. The full set of norms may be downloaded from www.psychonomic.org/archive.
\end{abstract}

Categorization provides our mental life with a sense of organization, allowing for the grouping of relatively diverse world entities into similar mental representations. This seems to be an advantage for our cognitive system because it contributes to efficient perception, communication, reasoning, and memory operations. The categorygeneration task is one of the empirical procedures used to explore how categorical information is organized in our minds. In this task, participants are instructed to generate exemplars of categories, after being prompted by the name of the category. Descriptive and computational analyses of the responses provide useful information about specific features of categories - for instance, exemplar dominance, exemplar typicality, and category size. Furthermore, the data stemming from this task can be used to derive norms, which have an important role in selecting, controlling, and manipulating verbal stimuli for empirical research in cognitive psychology, particularly in the areas of memory and language. The studies about retrieval-induced forgetting (e.g., Anderson, Bjork, \& Bjork, 1994) and false memories (e.g., Dewhurst \& Anderson, 1999; Seamon, Luo, Schlegel, Greene, \& Goldenberg, 2000) are examples of the recent application of these norms in memory research.

The study by Battig and Montague (1969) has been the most prominent work to have produced category norms for adults; its methodology has been applied in many other studies in different languages (e.g., in Dutch/Flemish, Ruts et al., 2004; in French, Marchal \& Nicolas, 2003; in Span- ish, Soto, Sebastián, Garcia, \& del Amo, 1994). With regard to Portuguese, the methodology of the study by Battig and Montague inspired the Pinto (1992) study that analyzed 46 of the original categories in a Portuguese adult sample.

Although to a lesser extent, the category-generation task has also been applied to children (e.g., Casey, 1989; Goikoetxea, 2000; Nelson, 1974; Posnansky, 1978; Price \& Connolly, 2006; Rosner \& Hayes, 1977). The majority of these studies compared the category norms of different ages and showed that older children generate more items for each category, probably due to a higher number of instances stored in their memory or to their increasing rate of articulation (Casey, 1989; Goikoetxea, 2000; Nelson, 1974; Rosner \& Hayes, 1977). However, younger children usually produce categories with a higher diversity. This means that when the number of different exemplars produced in a given category is divided by the total production for that category, younger children show more different exemplars (Goikoetxea, 2000; Nelson, 1974). This could be the result of the great amount of idiosyncratic and/or inappropriate responses generated by younger children. This finding seems to indicate that categories come to (1) be better established, (2) be composed of more stable exemplars, and (3) have more definite boundaries throughout development (Nelson, 1974). These studies have also shown that the adult category norms might not be directly generalizable to children, since knowledge of category exemplars tends to differ through life span (Price 
\& Connolly, 2006). For some categories, the correlations between the generation frequency of children and adults are weak (Casey, 1989), which suggests caution in the application of adult norms to young children.

Up until now, this kind of study with a child population has been nonexistent in Portugal, which has sometimes prevented the development of further research studies that require categorical materials adapted to children. In conducting child studies in cognitive psychology with categorical materials, it is important to know which exemplars are familiar for them and to identify the dominant exemplars for their age. For instance, studies about category typicality (e.g., Hasselhorn, 1992; Jerger \& Damian, 2005), false memories (e.g., Howe, 2006), cued recall (e.g., Cooper \& Newman, 1987), and interference in children (e.g., Howe, 2004) have used materials that require the knowledge stemming from category norms specifically derived from children.

Thus, in order to contribute to the knowledge about categorization in children and to promote the conduction of further studies in developmental cognitive psychology using the Portuguese language, the present study aims to provide children's category norms for a Portuguesespeaking population.

\section{METHOD}

\section{Participants}

Three hundred children in three age groups participated in this study: 100 preschoolers ( 54 male, 46 female), from 3 years 1 month to 4 years 11 months, with a mean age of 4 years 3 months; $100 \mathrm{sec}$ ond graders ( 49 male, 51 female), from 7 years 0 months to 8 years 11 months, with a mean age of 7 years 9 months; and 100 preadolescents (49 male, 51 female), from 11 years 1 month to 12 years 11 months, with a mean age of 11 years 10 months. All of the participants were native speakers of Portuguese, they were mostly from middle-class backgrounds, and they were recruited in kindergartens and elementary schools in three different cities of Portugal (Lisbon, Oeiras, and Vila Franca de Xira).

\section{Materials}

The categories used in this study were selected from the Battig and Montague (1969) study (using the Portuguese version of Pinto, 1992), with the exceptions described next. The original names of the categories Four-Footed Animals and Alcoholic or Nonalcoholic Beverages from Battig and Montague were simplified as Animals and Drinks to make them more understandable by the younger children. Price and Connolly (2006) and Goikoetxea (2000) did the same adaptations in their work with child samples. The category Food, included in the Goikoetxea study, was one of the categories selected in this study because it was thought that young children could generate exemplars for it. To select the categories for each age, several teachers from kindergartens and elementary schools were consulted to give their opinions about the categorical knowledge for each age. On the basis of this information, and taking into consideration the time duration of the task, the number of categories tested differed in the three age groups: 13 for preschoolers (Animals, Articles of Clothing, Articles of Furniture, Boys' Names, Colors, Drinks, Food, Fruits, Girls' Names, Kitchen Utensils, Parts of the Human Body, Toys, Vehicles) 17 for second graders (the previous 13 categories plus an additional four: Countries, Musical Instruments, Professions, Sports) and 21 for preadolescents (the previous 17 categories plus an additional four: Cities, Flowers, Trees, Vegetables).

A booklet with one page per category was used to collect the responses of the participants. To control for order effects, the position of each category in the booklet was randomized, except for the categories Girls' Names and Boys' Names, which were deliberately separated from each other to avoid contamination of female and male exemplars (e.g., Joana and João). Thus, different sets of category orders were constructed for each individual and presented with a cover page for registration of identification data.

\section{Procedure}

All of the children were tested individually, except the preadolescents, who performed the task in small groups (18-20 children in each group). In this last age group, the participants wrote the responses in the booklet, whereas for the other age groups, the responses were given orally and marked down by the experimenter. The oral responses were also recorded by a tape recorder so it would be possible to check the answers if necessary.

The oral instructions given by the experimenter were adapted to the participants' age. The participants were instructed to say or write (depending on the age group) as many exemplars as they could provide for each category, as fast as possible. Before starting the task, they were given a trial example. For the youngest group, the task was presented as a game, to motivate the children's collaboration, and in a few cases, a second example was offered to help them better understand the task. The instruction for the category Articles of Furniture was complemented with additional information concerning its meaning, because its name appeared to be unfamiliar for some preschoolers. In this case, after the name of the category, it was explained that the participants should provide names of "things from home."

Since verbal fluency studies have shown that the number of words produced in verbal fluency tasks increases with age (e.g., Kave, 2006; Sauzeon, Lestage, Raboutet, N'Kaoua, \& Claverie, 2004), the time limit of response for each category differed according to the age group: $30 \mathrm{sec}$ for preadolescents; $60 \mathrm{sec}$ for second graders; and $90 \mathrm{sec}$ for preschoolers. However, for preschoolers and second graders, the experimenter marked the sheet of paper as soon as the responses reached the 30-sec mark, to allow age comparisons within the same time limit. Because of these differences, the sessions lasted between 15-20 min for older children, 20-25 min for second graders, and 25-30 min for younger children.

\section{RESULTS AND DISCUSSION}

All the meaningful and legible responses were registered in the database even when they did not belong to the category. In the case of written responses, the spelling errors were corrected but the words were kept in their original forms as much as possible. The criteria to group words together included: singulars and plurals, feminine and masculine, and diminutives. For all these cases, the form with the highest frequency was registered. The category Animals was one exception: Both female and male exemplars of animals were included because they often imply different generic names. The exemplars that were subclasses of other exemplars (e.g., light blue and blue) or synonymous (car and automobile) were also entered as separate instances.

Category-generation norms for the three age groups are provided in the archived material. For each of the three groups, the archived material presents the tested categories in alphabetical order, and for each category, a listing of all the exemplars with a frequency above 5, ranked in order of production frequency (the complete norms can be obtained from the first author), and an English translation of each term, to facilitate understanding of the findings. The norms for preschoolers presents a first column (Total) with the frequency of all exemplars produced within $90 \mathrm{sec}$, and the following three columns discriminate the frequency between 0 and $30 \mathrm{sec}, 30$ and 
Table 1

Number of Children Responding $(N)$ and Mean Number of Responses $(M)$ per Category

\begin{tabular}{|c|c|c|c|c|c|c|}
\hline & \multicolumn{2}{|c|}{ Preschoolers } & \multicolumn{2}{|c|}{$\begin{array}{l}\text { Second } \\
\text { Graders }\end{array}$} & \multicolumn{2}{|c|}{ Preadolescents } \\
\hline & $N$ & $M$ & $N$ & $M$ & $N$ & $M$ \\
\hline Animals & 99 & 4.19 & 100 & 6.70 & 100 & 8.11 \\
\hline Articles of clothing & 100 & 3.53 & 100 & 5.83 & 99 & 6.80 \\
\hline Articles of furniture & 100 & 3.08 & 85 & 4.06 & 100 & 5.13 \\
\hline Boys' names & 99 & 2.87 & 100 & 6.35 & 100 & 8.01 \\
\hline Colors & 100 & 4.29 & 100 & $\mathbf{7 . 4 1}$ & 100 & 8.11 \\
\hline Drinks & 100 & 3.06 & 100 & 4.60 & 100 & 5.52 \\
\hline Food & 100 & 3.65 & 100 & 5.42 & 99 & 6.01 \\
\hline Fruits & 98 & 2.97 & 100 & 5.70 & 100 & 6.19 \\
\hline Girls' names & 99 & 2.81 & 100 & 6.55 & 100 & 8.54 \\
\hline Kitchen utensils & 98 & 3.16 & 100 & 5.33 & 100 & 5.52 \\
\hline Parts of human body & 100 & 4.08 & 100 & 7.04 & 100 & 7.35 \\
\hline Toys & 100 & 2.99 & 100 & 4.42 & 100 & 4.15 \\
\hline Vehicles & 72 & 2.53 & 96 & 4.91 & 100 & 5.91 \\
\hline $\begin{array}{l}\text { Countries } \\
\text { Musical instruments }\end{array}$ & & & $\begin{array}{l}96 \\
97\end{array}$ & $\begin{array}{l}5.15 \\
4.36\end{array}$ & $\begin{array}{r}99 \\
100\end{array}$ & 6.85 \\
\hline $\begin{array}{l}\text { Musical instruments } \\
\text { Professions }\end{array}$ & & & $\begin{array}{l}91 \\
97\end{array}$ & $\begin{array}{l}4.36 \\
4.09\end{array}$ & $\begin{array}{l}100 \\
100\end{array}$ & $\begin{array}{l}3.86 \\
476\end{array}$ \\
\hline Sports & & & 93 & 4.00 & 98 & 5.44 \\
\hline Cities & & & & & 100 & 5.98 \\
\hline Flowers & & & & & 100 & 3.73 \\
\hline Trees & & & & & 98 & 4.22 \\
\hline Vegetables & & & & & 100 & 4.64 \\
\hline
\end{tabular}

$60 \mathrm{sec}$, and 60 and $90 \mathrm{sec}$. Because the second graders had a time limit of $60 \mathrm{sec}$, this last column was omitted from the table. For preadolescents, only the Total column was presented, which corresponds to the time limit of $30 \mathrm{sec}$. The archived material also displays the frequency with which each exemplar was produced in the first place (1st) and the number of responses distributed according to the gender of the participant, female (F) and male (M).

Important characteristics of the data are highlighted in the accompanying tables, allowing for comparisons between the different categories and age groups, concerning productivity, category size, idiosyncratic and inappropriate responses, and commonality and diversity indexes. Table 5 also provides information about the correlation between instance frequencies for the three children's groups in this study, and between those values and the adult values obtained by Pinto (1992).

The number of children that provided exemplars for the categories and the mean number of responses within the same time limit $(30 \mathrm{sec}$ ) are presented in Table 1. Not surprisingly, the number of responses for each category increased with age (except for the category Toys), probably reflecting a general increase of vocabulary and higher speed of responses throughout development. The decrease in number of responses in the category Toys, from second graders to preadolescents, could reflect the implication of children's experience in their access to the exemplars, with older children likely to have less involvement with this type of activity than the second graders.

The information about the category size was obtained by excluding the idiosyncratic responses from the number of exemplars for each category (displayed in Table 2). Those values were divided by the $N$ of that category and multiplied by 100 to allow comparisons between the categories and the different age groups. Comparing the
13 categories that were common to all three age groups, there was no single common category that had the largest size for the three age groups. Still, some categories, such as Food, Animals, and Girls' Names, have a substantially large number of elements at all ages. On the other hand, Colors and Fruits were relatively small categories for children of any age, as is usually referenced in the adult and child literature (e.g., Nelson, 1974).

Idiosyncratic responses are all the exemplars generated by only one individual, and the inappropriate responses correspond to the responses that do not belong to the category.

Table 2

Number of Exemplars Generated Without Idiosyncratic Responses As a Function of $\boldsymbol{N}$ per Category

\begin{tabular}{lccc}
\hline & Preschoolers & $\begin{array}{c}\text { Second } \\
\text { Graders }\end{array}$ & Preadolescents \\
\hline Animals & 48.48 & 68.00 & 87.00 \\
Articles of clothing & 25.00 & 38.00 & 37.37 \\
Articles of furniture & 51.00 & 38.82 & 37.00 \\
Boys'names & 40.40 & 59.00 & 53.00 \\
Colors & 19.00 & 24.00 & 27.00 \\
Drinks & 20.00 & 31.00 & 51.00 \\
Food & 51.00 & 52.00 & 55.56 \\
Fruits & 15.31 & 28.00 & 31.00 \\
Girls' names & 44.44 & 69.00 & 77.00 \\
Kitchen utensils & 42.86 & 44.00 & 39.00 \\
Parts of human body & 35.00 & 49.00 & 53.00 \\
Toys & 43.00 & 43.00 & 40.00 \\
Vehicles & 23.61 & 26.04 & 32.00 \\
Countries & & 48.96 & 52.53 \\
Musical instruments & & 27.84 & 37.00 \\
Professions & & 47.42 & 65.00 \\
Sports & & 46.24 & 40.82 \\
Cities & & & 55.00 \\
Flowers & & & 26.00 \\
Trees & & & 29.59 \\
Vegetables & & 37.00 \\
\hline
\end{tabular}


Table 3

Percentage of Idiosyncratic Responses (ID) and Percentage of Inappropriate Responses (IN) per Category

\begin{tabular}{|c|c|c|c|c|c|c|}
\hline & \multicolumn{2}{|c|}{ Preschoolers } & \multicolumn{2}{|c|}{$\begin{array}{l}\text { Second } \\
\text { Graders }\end{array}$} & \multicolumn{2}{|c|}{ Preadolescents } \\
\hline & ID & $\mathbf{I N}$ & ID & IN & ID & IN \\
\hline Animals & 6.02 & 0.48 & 9.25 & 1.94 & 3.95 & 0.12 \\
\hline Articles of clothing & 4.82 & 0.85 & 5.49 & 0.69 & 3.42 & 1.03 \\
\hline Articles of furniture & 22.08 & 57.79 & 13.91 & 20.20 & 8.58 & 15.98 \\
\hline Boys' names & 13.73 & 2.79 & 6.30 & 0.16 & 6.24 & 1.25 \\
\hline Colors & 0.70 & 0.47 & 2.43 & 0.81 & 0.99 & 0.25 \\
\hline Drinks & 6.54 & 0.98 & 8.70 & 0.43 & 6.52 & 0.18 \\
\hline Food & 7.95 & 0.27 & 10.15 & 0.55 & $7.56^{2}$ & 0.00 \\
\hline Fruits & 3.09 & 1.68 & 2.28 & 0.70 & 1.78 & 0.00 \\
\hline Girls' names & 14.03 & 2.85 & 8.40 & 0.31 & 5.85 & 2.22 \\
\hline Kitchen utensils & 14.19 & 26.87 & 14.26 & 10.32 & 8.51 & 3.44 \\
\hline Parts of human body & 1.72 & 0.49 & 4.12 & 0.71 & 2.31 & 0.14 \\
\hline Toys & 26.42 & 0.67 & 23.76 & 0.00 & 13.01 & 0.00 \\
\hline Vehicles & 5.49 & 0.40 & 7.01 & 3.87 & 4.40 & 3.72 \\
\hline Countries & & & 13.36 & 24.29 & 5.90 & 4.82 \\
\hline Musical instruments & & & 3.07 & 1.61 & 3.41 & 0.17 \\
\hline Professions & & & 29.97 & 15.64 & 11.55 & 1.26 \\
\hline Sports & & & 15.86 & 11.75 & 5.44 & 0.92 \\
\hline Cities & & & & & 12.04 & 4.68 \\
\hline Flowers & & & & & 6.70 & 2.14 \\
\hline Trees & & & & & 5.31 & 1.42 \\
\hline Vegetables & & & & & 3.45 & 3.23 \\
\hline
\end{tabular}

This last measure was obtained by the classification done by three examiners. The responses were always classified as inappropriate when two of these examiners agreed that the word did not belong to the category. The percentages of idiosyncratic and inappropriate responses were calculated as a function of the number of responses given for each category - that is, dividing the number of idiosyncratic or inappropriate responses by the total number of responses for that category. As can be seen in Table 3, the percentage of inappropriate responses was very high for the category Articles of Furniture in all ages. Moreover, the inappropriate responses for Kitchen Utensils in preschoolers and Countries and Professions in second graders were above $15 \%$. This seems to indicate that the boundaries of these categories are not yet well established in these ages, which suggests that these particular categories should be used with caution in further research.

The commonality index provides information about the accordance level between the participants in relation to the more representative exemplars of the category. It is calculated by adding the frequency of the three first exemplars and then dividing by the total frequency production for the category and age group. Table 4 shows that the category Fruits presents the highest indicator of concordance for all ages, with regard to the 13 common categories. The diversity index gives information about the variability of each category - that is, the degree to which the exemplars are distinct. It is calculated by dividing the number of exemplars (including the idiosyncratic responses) by the total number of responses for that category and age group. As can be seen in Table 4, among the 13 common categories, the category Toys presents the highest level of diversity in all age groups. We believe that the main reason for this result derives from the observation that this category included many names of common objects that could serve as toys in certain circumstances (e.g., chair) and also brands (e.g., Playmobil). Mostly for younger children, pretend play implies the use of all types of objects that the adults use for nonplay activities in their routine life, a fact that could have increased the diversity value for this category. In line with this idea, this category was the one that showed the highest percentage of idiosyncratic responses (see Table 3).

The correlations between the instance frequencies of different ages were generally high (averages from .79 to .91 , respectively, for the correlation between preschoolers and preadolescents and between second graders and preadolescents; see Table 5), with the highest values for the categories Colors and Fruits, probably because they are the smallest categories. Table 5 also displays the correlations between the adult norms for a Portuguese population, obtained by Pinto (1992), and the children's norms of this study. The categories Animals, Food, and Drinks were not included in the analyses because in the adult study they were not tested in exactly the same way. Adult norms also strongly correlate with the children's norms, except for the categories Boys' Names (from .51 to .72) and Girls' Names (from .32 to .47), in which the correlation values were lower, probably because these categories are the most affected by the temporal distance between the two studies. In general, the highest correlation was obtained between the second graders and the preadolescents (average .91) and the lowest between the preschoolers and the adults (average .69).

The high correlations of instance frequencies observed in most of the categories for different ages seem to indicate that the pattern of responses across categories remains relatively stable throughout development. However, the low correlations for some other categories and also the observed discrepancy in the dominant exemplars within some 
Table 4

Commonality Index (C) and Diversity Index (DI) for Each Category

\begin{tabular}{|c|c|c|c|c|c|c|}
\hline & \multicolumn{2}{|c|}{ Preschoolers } & \multicolumn{2}{|c|}{$\begin{array}{l}\text { Second } \\
\text { Graders }\end{array}$} & \multicolumn{2}{|c|}{ Preadolescents } \\
\hline & $\mathrm{CI}$ & DI & CI & DI & CI & DI \\
\hline Animals & .27 & .18 & .21 & .19 & .23 & .15 \\
\hline Articles of clothing & .45 & .12 & .34 & .12 & .32 & .09 \\
\hline Articles of furniture & .22 & .37 & .35 & .23 & .31 & .16 \\
\hline Boys' names & .19 & .28 & .18 & .16 & .22 & .13 \\
\hline Colors & .37 & .05 & .31 & .06 & .32 & .04 \\
\hline Drinks & .54 & .13 & .37 & .15 & .28 & .16 \\
\hline Food & .25 & .22 & .28 & .20 & .29 & .17 \\
\hline Fruits & .63 & .08 & .40 & .07 & .36 & .07 \\
\hline Girls' names & .18 & .30 & .15 & .19 & .16 & .15 \\
\hline Kitchen utensils & .20 & .28 & .24 & .23 & .24 & .16 \\
\hline Parts of human body & .32 & .10 & .25 & .11 & .29 & .10 \\
\hline Toys & .23 & .41 & .25 & .33 & .32 & .23 \\
\hline Vehicles & .49 & .15 & .38 & .12 & .36 & .10 \\
\hline Countries & & & .32 & .23 & .33 & .14 \\
\hline Musical instruments & & & .40 & .09 & .35 & .10 \\
\hline Professions & & & .21 & .42 & .21 & .25 \\
\hline Sports & & & .30 & .27 & .41 & .13 \\
\hline Cities & & & & & .33 & .21 \\
\hline Flowers & & & & & .47 & .14 \\
\hline Trees & & & & & .38 & .12 \\
\hline Vegetables & & & & & .36 & .11 \\
\hline
\end{tabular}

of the categories seem to justify the use of different category norms for distinct age groups. For instance, whereas for preadolescents and adults the dominant exemplar of the category Animals was a domestic animal (dog), for second graders and preschoolers it was a wild animal (lion and elephant), with the exemplar $\operatorname{dog}$ listed in $2 \mathrm{nd}$ and 10th places, respectively. This result is interesting because the same kind of shift from wild to domestic animals was reported as early as in the Nelson (1974) normative study.

Although it would be interesting to elaborate on these results, taking into account different concept measures such as linguistic frequency, familiarity, and age of acqui- sition, this could not be done in a systematic way. At the present time, Portuguese materials relating to these measures are still scarce, and sufficient information is not currently available for all the category names or exemplars of this study. Even so, we selected three of the categoriesAnimals, Fruits, and Vehicles-for which it is possible to have information about age of acquisition and familiarity, thanks to a very recent study conducted by Marques, Fonseca, Morais, \& Pinto (2007). We could observe that, in general, the dominant exemplars are acquired first and are more familiar than the less frequent exemplars (with a frequency between 6 and 7). For example, the dominant

Table 5

Correlation Values Between the Instance Frequencies of Different Age Groups of Children and the Adult Sample of Pinto (1992)

\begin{tabular}{lcccccc}
\hline & $3 / 4-7 / 8$ & $3 / 4-11 / 12$ & $7 / 8-11 / 12$ & 3/4-Adults & 7/8-Adults & 11/12-Adults \\
\hline Animals & .81 & .58 & .85 & & & \\
Articles of clothing & .93 & .83 & .93 & .80 & .89 & .93 \\
Articles of furniture & .69 & .74 & .92 & .62 & .86 & .87 \\
Boys' names & .77 & .79 & .87 & .51 & .65 & .72 \\
Colors & .96 & .94 & .96 & .91 & .96 & .98 \\
Drinks & .84 & .80 & .95 & & & \\
Food & .90 & .83 & .93 & & & \\
Fruits & .93 & .92 & .96 & .89 & .92 & .93 \\
Girls' names & .77 & .65 & .83 & .32 & .47 & .45 \\
Kitchen utensils & .82 & .80 & .93 & .67 & .89 & .88 \\
Parts of human body & .84 & .85 & .96 & .77 & .95 & .96 \\
Toys & .84 & .79 & .94 & .66 & .76 & .72 \\
Vehicles & .89 & .78 & .93 & .71 & .82 & .80 \\
Countries & & & .95 & & .86 & .94 \\
Musical instruments & & & .90 & & .85 & .90 \\
Professions & & & .86 & & .77 & .83 \\
Sports & & .86 & & .81 & .95 \\
Cities & & & & & .92 \\
Flowers & & & & & .83 \\
Trees & & & & & .92 \\
Vegetables & & & & & & \\
\hline
\end{tabular}


exemplar in the category Vehicles for all three age groups was car, with a mean age of acquisition of 1.76 and a familiarity of 1.64 , whereas the less frequent exemplars were helicopter (for preschoolers and second graders) and van (for preadolescents), with age of acquisition values of 3.05 and 2.52 and familiarity values of 1.74 and 2.40 , respectively.

In closing, caution should be used in generalizing these norms, obtained in Portugal, to other Portuguesespeaking populations in Africa and America, since category-generation norms can be influenced by linguistic peculiarities and by the specific culture of each country or geographical region. For example, although in the same language as the Battig and Montague (1969) study, specific norms have also been produced in English for other countries, such as Australia (Casey \& Heath, 1988) and New Zealand (Marshall \& Parr, 1996). But despite these restrictions about generalizing data, common to any type of norms, the present study has produced a useful tool for further research, since it provides children's category norms for a Portuguese-speaking population for the first time. Together with recent associative norms already established for the Portuguese children's population (Carneiro, Albuquerque, Fernandez, \& Esteves, 2004), this set of data is expected to contribute to the increment of further studies in developmental cognitive psychology that require materials adapted to Portuguese-speaking children of different ages.

\section{AUTHOR NOTE}

The first author was supported by Fundação para a Ciência e Tecnologia (FCT). A.F. was supported by the Spanish Ministry of Education and Science (Project SEJ2005-03210) and by Junta de Castilla y León (Project SA031A-06). We thank Amélia Lopes and Flávia Afonso for data collection and Francisco Esteves and Frederico Marques for their comments on the manuscript. Thanks also to Adriana and Frederico Godinho for their help in transcribing the exemplars. We also gratefully acknowledge an anonymous reviewer's comments. Correspondence concerning this article should be addressed to $P$. Carneiro, Universidade Lusófona de Humanidades e Tecnologias, Departamento de Psicologia, Av. do Campo Grande, 376, 1749-024 Lisbon, Portugal (e-mail: mpcarneiro@usal.es).

\section{REFERENCES}

Anderson, M. C., BJoRK, R. A., \& BJorK, E. L. (1994). Remembering can cause forgetting: Retrieval dynamics in long-term memory. Journal of Experimental Psychology: Learning, Memory, \& Cognition, 20, 1063-1087.

BaTtiG, W. F., \& MontagUE, W. E. (1969). Category norms for verbal items in 56 categories: A replication and extension of the Connecticut category norms. Journal of Experimental Psychology Monographs, 80(3, Pt. 2), 1-46.

Carnetro, P., Albuquerque, P., Fernandez, A., \& Esteves, F. (2004). Normas de associação livre de 16 palavras portuguesas para crianças de diferentes faixas etárias. Laboratório de Psicologia, 2, 49-76.

CASEY, P. J. (1989). Category norms across the lifespan. In M. A. Luszcz \& T. Nettelbeck (Eds.), Psychological development: Perspectives across the life-span (pp. 141-150). Amsterdam: North-Holland.

Casey, P. J., \& Heath, R. A. (1988). Category norms for Australians. Australian Journal of Psychology, 40, 323-339.

COOPER, M., \& Newman, S. (1987). Cue-target compatibility in children's cued recall. American Journal of Psychology, 100, 167-178.

Dewhurst, S. A., \& ANDERSon, S. J. (1999). Effects of exact and category repetition in true and false recognition memory. Memory \& Cognition, 27, 664-673.
GoIKoetXEa, E. (2000). Frecuencia de producción de las respuestas a 52 categorias verbales en niños de primaria. Psicológica, 21, 61-89.

HASSELHORN, M. (1992). Task dependency and the role of category typicality and metamemory in the development of an organizational strategy. Child Development, 63, 202-214.

HowE, M. L. (2004). The role of conceptual recoding in reducing children's retroactive interference. Developmental Psychology, 40, 131-139.

HowE, M. L. (2006). Developmentally invariant dissociations in children's true and false memories: Not all relatedness is created equal. Child Development, 77, 1112-1123.

JERGER, S., \& DAMIAN, M. F. (2005). What's in a name? Typicality and relatedness effects in children. Journal of Experimental Child Psychology, 92, 46-75.

KAVE, G. (2006). The development of naming and word fluency: Evidence from Hebrew-speaking children between ages 8 and 17. Developmental Neuropsychology, 29, 493-508.

MARCHAL, A., \& NiCOLAS, S. (2003). Normes de production catégorielle pour 38 catégories sémantiques: Étude sur des sujets jeunes et âgés. L'Année Psychologique, 103, 313-366.

Marques, J. F., Fonseca, F. L., Morais, A. S., \& Pinto, I. A. (2007). Estimated age of acquisition norms for 834 Portuguese nouns and their relation with other psycholinguistic variables. Behavior $R e-$ search Methods, 39, 439-444.

Marshall, C. E., \& PARR, W. V. (1996). New Zealand norms for a subset of Battig and Montague's (1969) categories. New Zealand Journal of Psychology, 25, 24-29.

NELSON, K. (1974). Variations in children's concepts by age and category. Child Development, 45, 577-584.

PıNTo, A. C. (1992). Medidas de categorização: Frequência de produção e de tipicidade. Jornal de Psicologia, 10, 10-15.

PosNansky, C. J. (1978). Category norms for verbal items in 25 categories for children in grades 2-6. Behavior Research Methods \& Instrumentation, 10, 819-832.

Price, H. L., \& ConNolly, D. A. (2006). BatMon II: Children's category norms for 33 categories. Behavior Research Methods, 38, 529-531.

ROSNER, S. R., \& HAYES, D. S. (1977). A developmental study of category item production. Child Development, 48, 1062-1065.

Ruts, W., De Deyne, S., Ameel, E., Vanpaemel, W., Verbeemen, T., \& STORMs, G. (2004). Dutch norm data for 13 semantic categories and 338 exemplars. Behavior Research Methods, Instruments, \& Computers, 36, 506-515.

Sauzeon, H., Lestage, P., Raboutet, C., N'Kaoua, B. \& Claverie, B. (2004). Verbal fluency output in children aged 7-16 as a function of the production criterion: Qualitative analysis of clustering, switching processes, and semantic network exploitation. Brain \& Language, 89, 192-202.

Seamon, J. G., Luo, C. R., Schlegel, S. E., Greene, S. E., \& GoldenBERG, A. B. (2000). False memory for categorized pictures and words: The category associates procedure for studying memory errors in children and adults. Journal of Memory \& Language, 42, 120-146.

Soto, P., Sebastián, M. V., Garcia, E., \& DEL Amo, T. (1994). Las categorias y sus normas en castellano. Madrid: Visor.

\section{ARCHIVED MATERIALS}

The following materials associated with this article may be accessed through the Psychonomic Society's Norms, Stimuli, and Data archive, www.psychonomic.org/archive.

To access these files, search the archive for this article using the journal name (Behavior Research Methods), the first author's name (Carneiro), and the publication year (2008).

FILE: Carneiro-2008.zip.

DESCRIPTION: The compressed archive file contains two files:

Carneiro(2008).txt, containing Portuguese exemplars in text format.

Carneiro(2008).xls, containing the above information in Excel spreadsheet format.

AUTHOR'S E-MAIL ADDRESS: mpcarneiro@usal.es.

(Manuscript received March 15, 2007; revision accepted for publication May 22, 2007.) 